\title{
Refractory Pleural Malignant Mesothelioma
}

National Cancer Institute

\section{Source}

National Cancer Institute. Refractory Pleural Malignant Mesothelioma. NCI Thesaurus.

Code C159675.

Pleural malignant mesothelioma that is resistant to treatment. 